\title{
STUDI PROTEKSI ELECTRIC SHOCK PADA INSTALASI RUMAH TINGGAL MENGGUNAKAN RESIDUAL CURRENT CIRCUIT BREAKER WITH INTERGRAL OVERLOAD PROTECTION
}

\author{
Sofyar $^{1)}$ \\ ${ }^{1}$ Jurusan Teknologi Listrik, Akademi Teknik Pembangunan Nasional Banjarbaru \\ Email: h.sofyar@gmail.com
}

\begin{abstract}
This paper offers a solution for securing a simple residential installation of the dangers of electric shock. In the introduction, the background of the importance of using a protection system in electrical installations is explained and some definitions related to electric shock and RCBO. For the part of the research method, the specifications of the RCBO used are displayed and the flow of the research is also shown. In the discussion and the results it is known that RCBO will trif if there is an overload, short circuit, and electric shock caused by direct contact with the live part. For nominal current (In) from RCBO, RCBO with a value of 6 Ampere and its current sensitivity $(\mathrm{I} \Delta \mathrm{n}=30 \mathrm{~mA})$ is chosen according to the RCBO on the market.
\end{abstract}

Keywords: electric shock, residual current circuit breaker

\section{PENDAHULUAN}

Energi listrik dalam pemanfaatannya bagi kehidupan manusia memegang peranan yang sangat penting sekarang ini, dimana kebanyakan peralatan yang digunakan baik di area industri, perkantoran, tempat ibadah, ruang publik, dan di rumah tinggal tergantung pada energi tersebut. Dari sekian banyak keuntungan yang didapatkan dengan pemanfaatan energi listrik tersebut, Quazani Abdallah dan Idir Hadi (2015) menyatakan bahwa listrik juga dapat membunuh atau menimbulkan luka parah pada orang dan merusak peralatan. Dikatakan oleh Hossein Mafi, Rami Yared, dan Layachi Bentabet (2019) bahwa arus bocor (leakage current), beban lebih (overload), dan hubung singkat (short-circuit) menyebabkan efek berbahaya pada tubuh manusia dan peralatan listrik. Karena dapat menyebabkan kejut listrik (electric shock) atau sengatan listrik dan dapat menjadi sumber api. Scheneider Electric juga menyebutkan bahwa setiap tahun, 400.000 terjadi kecelakaan karena listrik dan 3000 orang menderita dari kecelakaan tersebut.

Peralatan-peralatan proteksi arus sisa atau yang dikenal dengan residual current devices (RCD), dikatakan oleh Jacques Schonek (2006) sebagai peralatan proteksi yang paling efektif melindungi manusia dan peralatan dari bahaya listrik pada sistem tegangan rendah. Untuk pemilihan peralatan RCD disebutkan pada Power Guide (2009), tergantung pada tingkat perlindungan yang diperlukan (sensitivitas ambang trip $\mathrm{I} \Delta \mathrm{n}$ ). Ada tiga kelompok sensitivitas dari RCD, yaitu sensitivitas tinggi ( $\mathrm{I} \Delta \mathrm{n} \leq 30 \mathrm{~mA})$, sedang $(\mathrm{I} \Delta \mathrm{n} \leq 500$ $\mathrm{mA})$, dan rendah (I $\Delta \mathrm{n}>0.5$ A). Pada Persyaratan Umum Instalasi Listrik (PUIL 2011) dikatakan bahwa untuk instalasi tegangan rendah, sistem dan perlengkapan, proteksi dasar umumnya berkaitan dengan proteksi terhadap sentuhan langsung (direct contact).

Menurut PT. PLN (persero) (2010) pelayanan listrik kepada pelanggan untuk saluran tegangan rendah 1 fasa dilayani dengan tegangan $220 \mathrm{~V}$ dan 220/380 V untuk 3 fasa, sedangkan untuk konfigurasi sambungannyan disesuaikan dengan besarnya daya tersambung.

\section{a. Electrical Shock}

Electric shock atau kejut listrik oleh Schneider Electric dan PUIL 2011 didefinisikan sebagai efek fisiologis akibat arus listrik yang melalui tubuh manusia. Hal tersebut dikatakan oleh Ashutosh Saxena, Supratim Ray, dan Rajiv K. Varma (2002) 
terjadi karena adanya kontak listrik dengan penghantar yang tidak ditanahkan atau dengan bagian yang dapat menghantarkan listrik dari peralatan listrik yang terbuka karena adanya kerusakan pada isolasi dasarnya. Bersentuhan dengan bagian listrik yang aktif baik secara langsung (direct contact) ataupun tidak langsung (indirect contact), dikatakan juga oleh Syukriyadin (2016) dapat menimbulkan kecelakaan yang memberikan dampak seperti luka bakar pada bagian tubuh, mengalami kejang, pingsan dan bahkan sampai mengalami kematian. Shashikumar K dan kawan-kawan (2019), merujuk dari peneliti sebelumnya Fricke dan Mose (1925), serta Alrawi dan kawan-kawan (2010), mengatakan bahwa electric shock sudah dirasakan pada arus bolak-balik sebesar $30 \mathrm{~mA}$ untuk ukuran tubuh manusia rata-rata.

\section{b. Residual Current Circuit Breaker with integral overload Protection (RCBO)}

Residual current circuit breaker with integral overload protection atau yang dikenal dengan RCBO oleh Dahari M. Siran pada National Conference on Electrical Safety (2011) disebutkan merupakan bagian dari peralatan proteksi terhadap arus sisa (residual current devices). Arus sisa (residual current) didefinisikan sebagai jumlah aljabar nilai arus listrik di semua konduktor aktif, pada waktu yang sama, di titik yang ditentukan suatu sirkit listrik pada instalasi listrik (PUIL 2011). RCBO dikatakan oleh Frantisek Stephan (2017) dirancang untuk instalasi rumah tinggal dan sejenisnya, yang dapat dioperasikan dengan mudah tanpa diperlukan keahlian khusus. RCBO didisain sebagai peralatan yang padu, menggabungkan fungsi dari RCD dalam hal ini earth leakage circuit breaker (ELCB) dengan circuit breaker atau miniature circuit breaker (MCB).

\section{c. Keterbaruan Penelitian}

Penelitian tentang electric shock juga pernah dilakukan oleh peneliti-peneliti sebelumnya, seperti Quazani Abdallah dan Idir Habi (2015) yang menjelaskan bagaimana pengaruh electric shock pada manusia dan peralatan pada instalasi listrik, namun tidak menjelaskan secara khusus alat yang digunakan serta bagaimana cara pemasangannya pada instalasi listrik. Syukriyadin (2016) juga meneliti mengenai proteksi terhadap kejut listrik (electric shock) dengan menggunakan earth leakage circuit breaker berbasis ardoino. Shashikumar dan kawan-kawan (2019) juga meneliti masalah proteksi terhadap electric shock dengan menggunakan residual current circuit breaker melalui simulasi simulink matlab akan tetapi tidak membahas rangkaian dan penempatan peralatan proteksinya pada instalasi listrik.

\section{METODE PENELITIAN}

Pada penelitian ini dilakukan studi untuk mengetahui bagaimana unjuk kerja dari RCBO yang diaplikasikan pada instalasi rumah tinggal yang memiliki 2 group atau kelompok beban pada rangkaian akhirnya. Untuk itu maka nantinya dibuat rangkaian listrik sederhana yang dapat menjadi refleksikan dari instalasi rumah tinggal yang sebenarnya.

\section{Bahan dan Alat}

1. Stop kontak. Digunakan untuk mendapatkan sumber tegangan listrik bagi piranti listrik yang lain. Disini diperlukan sebanyak 4 buah.

2. Sakelar tunggal dan sakelar seri. Digunakan Untuk menghidupkan (menghubungkan) dan mematikan (memutuskan) sebuah beban atau kelompok beban (biasanya lampu). Masingmasing diperlukan sebanyak 2 buah.

3. Lampu pijar $5 \mathrm{~W} / 220 \mathrm{~V}$ sebanyak 6 buah. Sebagai beban untuk penerangan.

4. Kabel tipe NYA $1,5 \mathrm{~mm}$. Berfungsi sebagai penghantar arus listrik pada rangkaian.

5. MCB atau miniature circuit breaker. Pada simulasi ini digunakan $\mathrm{MCB}$ dengan rating arus In $6 \mathrm{~A}$ dan kapasitas pemutusan $4500 \mathrm{~A}$ pada tegangan $230 \mathrm{~V}$ AC dan frekuensi $50 \mathrm{~Hz}$, sebanyak 2 buah. Fungsinya sebagai peralatan pengaman hubung singkat dan arus lebih untuk setiap grup atau kelompok beban.

6. RCBO atau residual current circuit breaker with integral circuit breaker. Digunakan untuk peralatan proteksi (manusia) terhadap bahaya kejut listrik (electric shock), hubung singkat, dan pembebanan lebih. Diperlukan sebanyak 1 buah.

7. Bahan dan peralatan lain (seperti: fitting lampu, panel hubung bagi (PHB), pipa PVC, klem, kotak hubung, sekrup, papan triplek, obeng, tang kombinasi, palu, cutter, dan peralatan instrumentasi). 
Tabel 1. Karakteristik Teknis RCBO (Sumber: Shneider Electric Indonesia 2019)

\begin{tabular}{|l|l|}
\hline \multicolumn{1}{|c|}{ Data Teknis (simbol) } & \multicolumn{1}{c|}{ Nilai (satuan) } \\
\hline Tegangan Operasi (Ue) & $230(\mathrm{~V}$ AC) \\
\hline Tegangan Insulasi (Ui) & $400(\mathrm{~V})$ \\
\hline $\begin{array}{l}\text { Tegangan Implus Withstand } \\
\text { (UImp) }\end{array}$ & $4(\mathrm{kV})$ \\
\hline Frekuensi (f) & $50(\mathrm{~Hz})$ \\
\hline Daya Tahan Elektris & $10000($ siklus) \\
\hline Daya Tahan Mekanis & $20000($ siklus) \\
\hline Derajat Proteksi & $20(\mathrm{IP})$ \\
\hline Suhu Pengoperasian & $-25 \ldots+55\left({ }^{\circ} \mathrm{C}\right)$ \\
\hline
\end{tabular}

\section{Alur Penelitian}

Adapun diagram alur jalannya penelitian dapat dilihat pada gambar 1 di bawah:

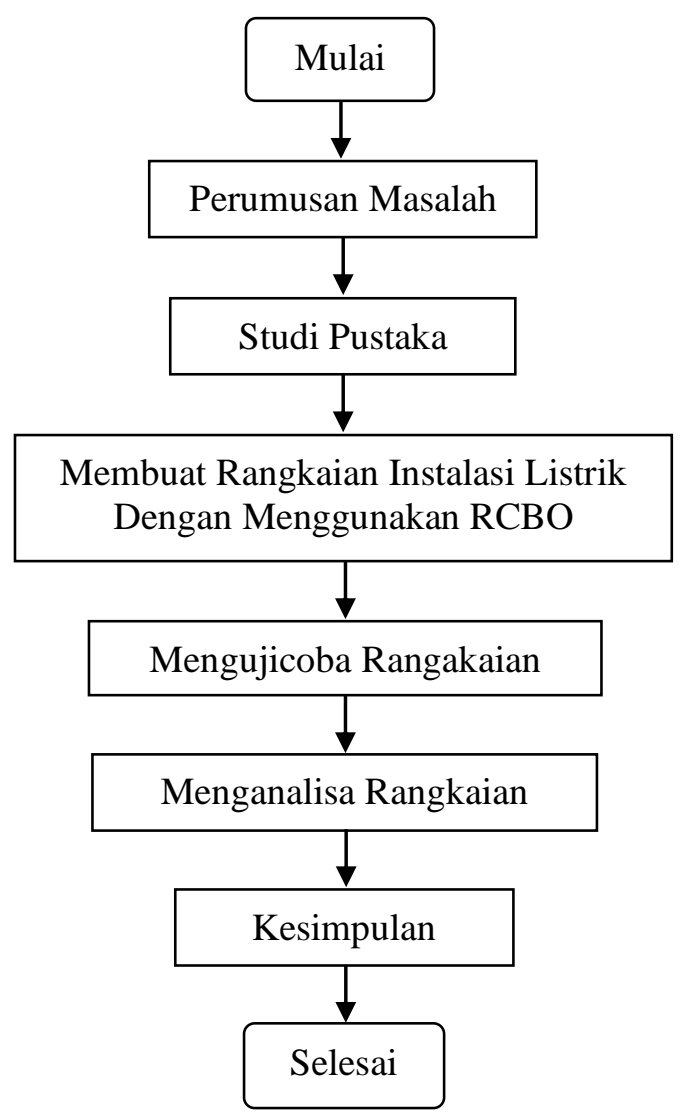

Gambar 1. Diagram alur penelitian

\section{HASIL DAN PEMBAHASAN}

\section{a. Hubungan Rangkaian RCBO Setelah KWH Meter}

Sebelum kabel fasa dari sumber listrik PLN disalurkan ke beban, dihubungkan dahulu ke RCBO bersama kabel netral. Selanjutnya output RCBO untuk kabel fasanya dihubungkan ke MCB dan untuk kabel netralnya dihubungkan ke konektor. Rangkaian RCBO dari kwh meter yang selanjutnya dihubungkan ke miniature circuit breaker (MCB) dapat diperlihatkan pada gambar 2 .

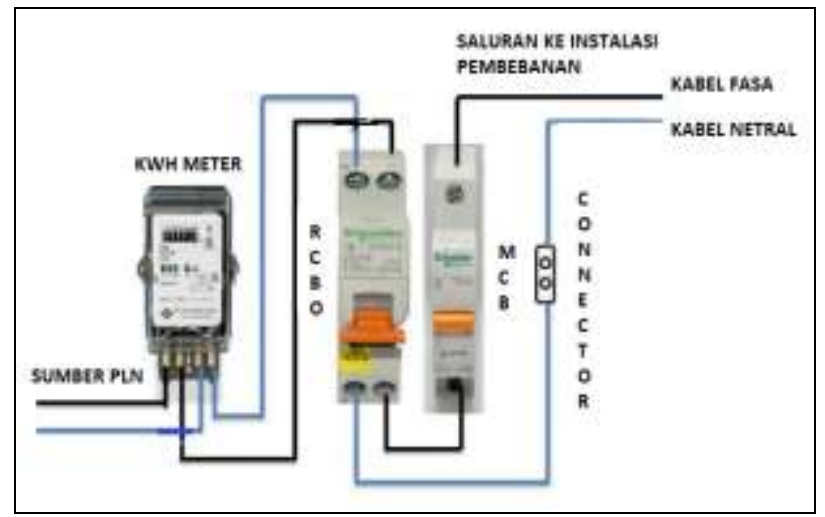

Gambar 2. Hubungan rangkaian RCBO dengan MCB [Sumber: https:/l www. Plcdroid.com/2020/10/pengertianrcbo.html]

\section{b. Rangkaian Instalasi Rumah Tinggal}

Untuk merefleksikan instalasi rumah tinggal sebenarnya maka dibuat rangkaian instalasi listrik sederhana dengan membuat pengelompokan beban dalam 2 group kelompok beban. Beban yang ada pada setiap kelompok beban terdiri dari 3 buah lampu pijar yang dikontrol oleh sakelar tunggal dan sakelar seri, serta 2 buah stop kontak. Adapun gambar rangkaiannya dapat dilihat pada gambar 3:

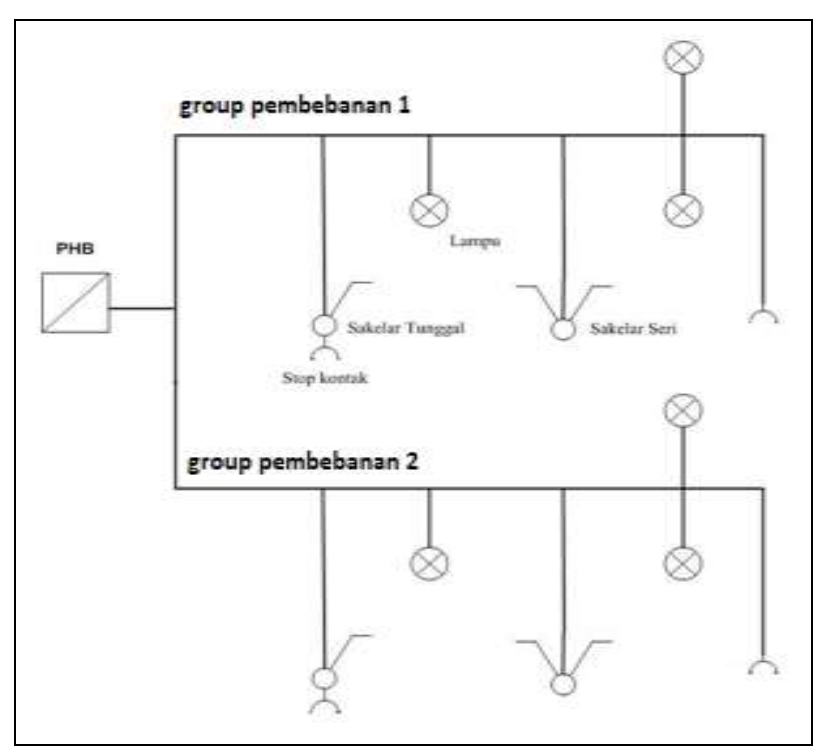

Gambar 3. Diagram tunggal instalasi listrik dengan 2 kelompok beban 
RCBO diletakan pada panel hubung bagi (PHB) bersama dengan 2 buah MCB untuk masingmasing group pembebanan.

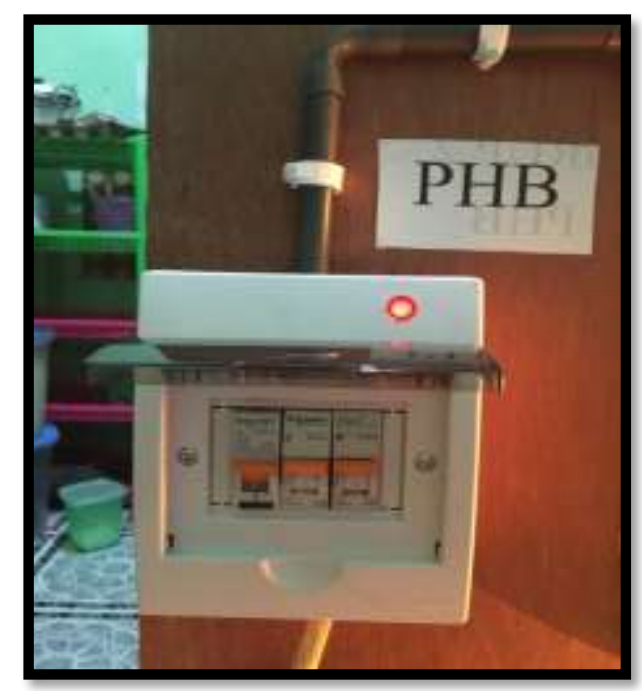

Gambar 4. Visual dari RCBO dan MCB pada panel hubung bagi untuk kondisi normal tidak ada gangguan

\section{c. Pengujian Rangkaian Instalasi RCBO}

Rangkaian instalasi listrik bila dioperasikan pada kondisi normal tidak ada gangguan maka berfungsi sebagaimana mestinya, dimana untuk masing-masing group pembebanan, sakelar tunggal akan menghidupkan dan mematikan 1 buah beban lampu dan sakelar seri akan menghidupkan serta mematinan 2 beban lampu lainnya. Untuk stop kontak bila dihubungkan dengan peralatan listrik akan menghidupkan atau menggerakan peralatan listrik tersebut.

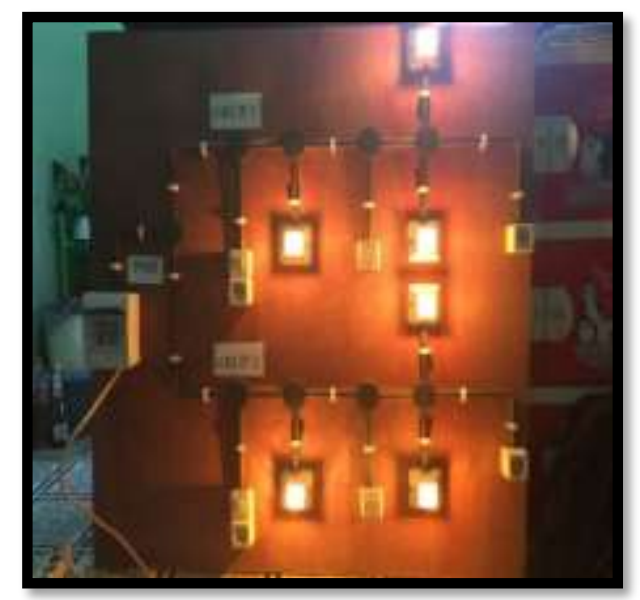

Gambar 5. Visual rangkaian instalasi sebagai refleksi instalasi rumah tinggal sederhana
Pengujian rangkaian instalasi RCBO ini dilakukan dengan 3 tipe pengujian, yaitu:

- Pengujian RCBO terhadap beban lebih (over load)

- Pengujian RCBO terhadap hubungan singkat (short circuit)

- Pengujian RCBO terhadap electric shock atau kejut listrik yang disebabkan oleh arus residu.

\section{c.1 Pengujian Beban Lebih}

Pengujian beban lebih pada RCBO dilakukan dengan cara memberikan pembebanan pada salah satu ataupun pada kedua group pembebanan dari rangkaian instalasi yang dilindungi oleh RCBO tersebut dengan beban yang lebih besar dari pada arus nominal dari $\mathrm{RCBO}\left(\mathrm{I}_{\mathrm{n}}\right.$ dari $\left.\mathrm{RCBO}\right)$. Pada penelitian ini besarnya $I_{n}$ RCBO pada rangkaian instalasi $\mathrm{RCBO}$ tersebut adalah $\mathrm{I}_{\mathrm{n}}=6$ Amper. Bila besarnya arus beban $\left(\mathrm{I}_{\text {Beban }}\right)>\mathrm{I}_{\mathrm{n}} \mathrm{RCBO}$ dan RCBO bekerja men-trip (memutuskan rangkaian) maka RCBO dikatakan berfungsi dengan baik mengamankan rangkaian insatalasi dari pembebanan lebih (overload). Pada gambar 6 diperlihatkan ketika rangkaian instalasi RCBO diberikan pembebanan dengan berbagai peralatan listrik.

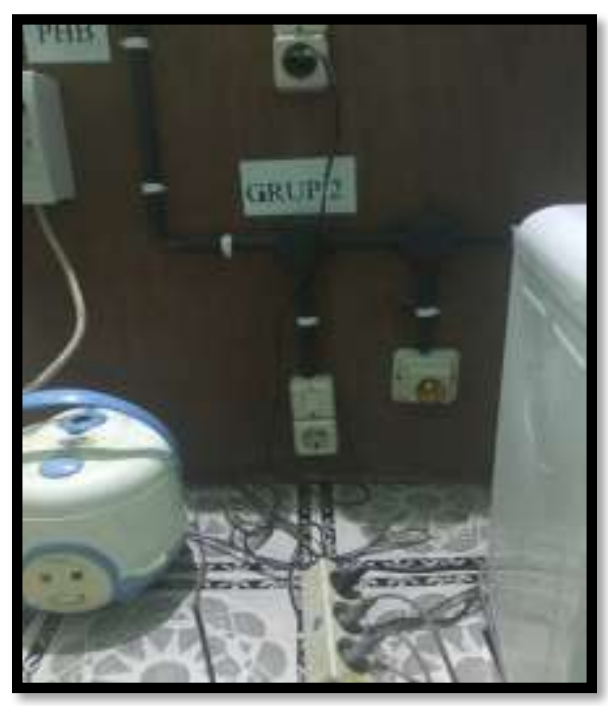

Gambar 6. Pembebanan rangkaian instalasi RCBO dengan berbagai peralatan listrik

Untuk kondisi RCBO pada panel hubung bagi (PHB) tampak RCBO yang sebelumnya pada kondisi on (rangkaian terhubung), sekarang berubah menjadi ke posisi off atau trif (rangkaian terputus). Hal ini diperlihatkan pada gambar 7, dimana RCBO dan MCB trif. Untuk MCB sendiri 
memang sengaja di off kan karena yang diuji hanya RCBO-nya saja.

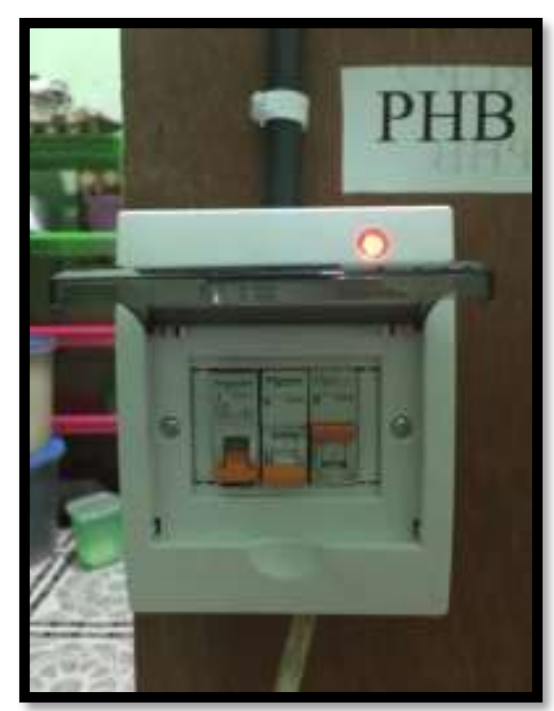

Gambar 7. Kondisi RCBO setelah dilakukan pembebanan

\section{c.2 Pengujian Hubung Singkat}

Pada pengujian hubung singkat dilakukan dengan menggabungkan (men-shortkan) antara bagian fase (yang bertegangan) dengan bagian netral (tidak bertegangan) pada stop kontak dari salah satu group pembebanan. Apabila RCBO melakukan trif setelah penggabungan kedua bagian tadi maka RCBO dikatakan bekerja dengan baik mengamankan rangkaian instalasi dari gangguan hubung singkat. Visual pengujian hubung singkat dapat dilihat pada gambar 8.

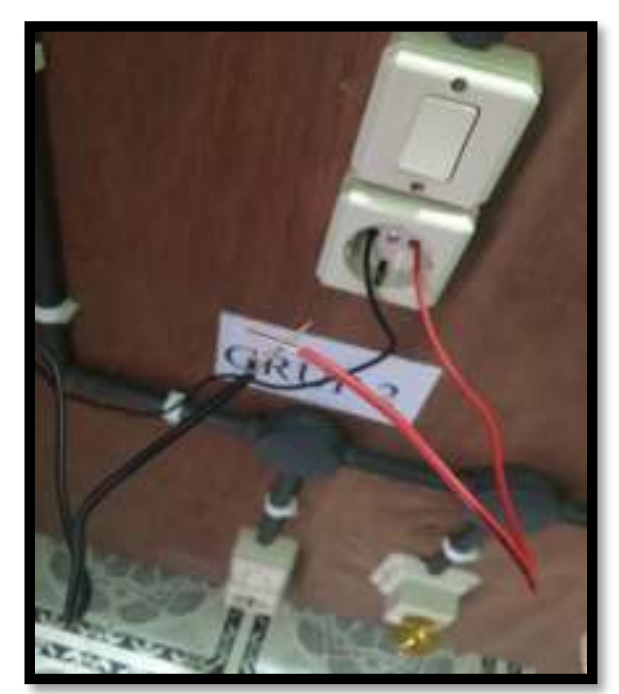

Gambar 8. Hubung singkat antara bagian fasa dengan netral pada salah satu group pembebanan
Untuk kondisi RCBO pada panel hubung bagi (PHB) diperlihatkan pada gambar 9.

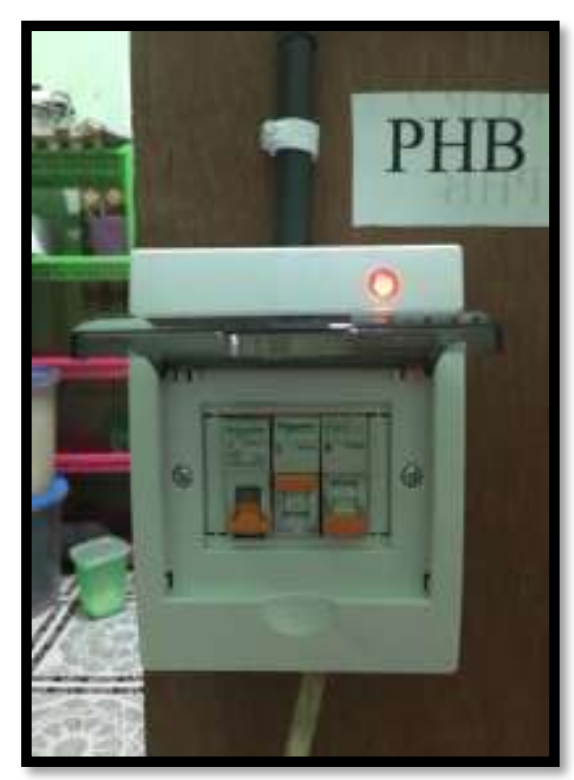

Gambar 9. Kondisi RCBO setelah terjadi hubung singkat pada beban

\section{c.3Pengujian Electric Shock}

Pengujian RCBO terhadap electric shock atau kejut listrik yang disebabkan oleh arus sisa (residual current) dilakukan dengan cara menghubungkan penghantar atau kabel fasa pada stop kontak dari salah satu group pembebanan ke tanah. Hal tersebut merefleksikan seseorang yang mengalami kontak langsung dengan bagian yang bertegangan, sehingga arus listrik mengalir dari rangkaian ke tanah melalui tubuh seseorang. Gambar 10 memperlihatkan pengujian RCBO terhadap electric shock.

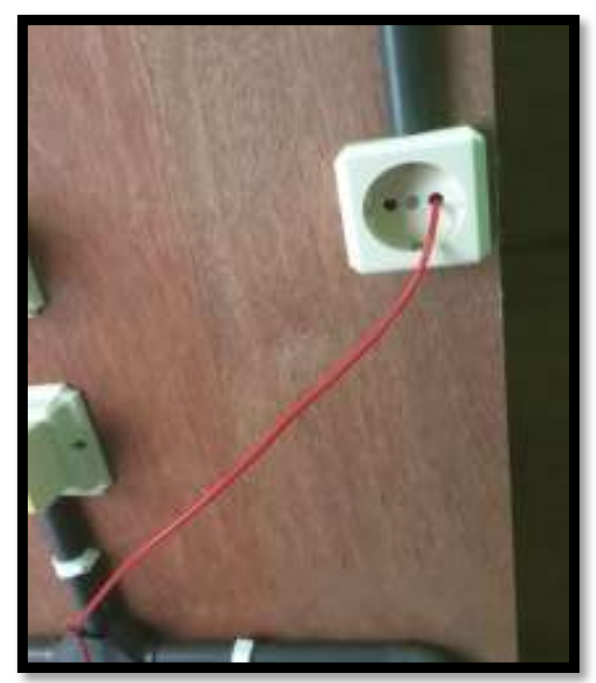

Gambar 10, Bagian fasa dari stop kontak yang dihubungkan ke tanah 
Tampak pada gambar, bagian yang bertegangan dari stop kontak yang dihubungkan ke tanah menggunakan kabel tipe NYA warna merah. Ini merupakan visual yang diperlihatkan dari sisi stop kontak, sedangkan dari sisi tanah atau ground ke stop kontak diperlihatkan pada gambar 11.

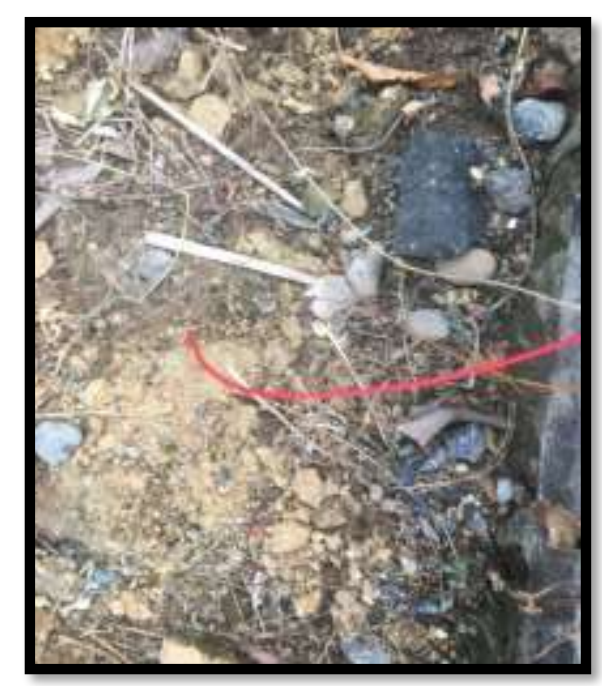

Gambar 11. Kabel yang menghubungkan bagian fasa dari stop kontak dengan tanah

Untuk kondisi RCBO pada panel hubung bagi (PHB) setelah dihubungkannya bagian fasa dari stop kontak dari salah satu group pembebanan ke tanah (ground) dapat dilihat pada gambar 12.

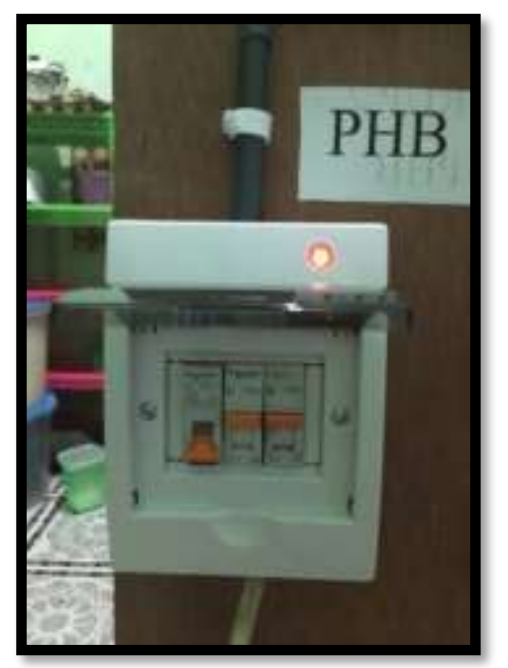

Gambar 12. Kondisi RCBO setelah bagian fasa stop kontak dihubungkan ke tanah

Dari gambar 12 tampak RCBO pada kondisi trif, hal ini menunjukan bahwa RCBO bekerja dengan baik sesuai fungsinya yaitu mampu mengamankan seseorang dari bahaya electric shock atau kejut listrik dengan cara memutuskan (trif) rangkaian dari sumber listriknya.

\section{d. Perhitungan Rating Arus RCBO}

Untuk menentukan besarnya rating arus nominal dari RCBO $\left(\mathrm{I}_{\mathrm{n}}\right)$ digunakan formulasi dari persamaan daya sistem arus bolak-balik (alternating current) 1 fasa, yaitu (Sunarno 2006):

$\mathrm{P}=$ V.I. $\cos \varphi$ atau

$\mathrm{I}=\frac{\mathrm{P}}{\mathrm{V} \cdot \cos \varphi}$

Dimana:

$\mathrm{P} \quad=$ Daya beban terpasang (Watt)

$\mathrm{V} \quad=$ Tegangan terpasang (Volt)

$\mathrm{I}=$ Arus listrik (Amper)

$\cos \varphi=$ Faktor daya

Besarnya daya terpasang $\mathrm{P}=900$ Watt dan tegangan terpasang $\mathrm{V}=220$ Volt dan $\cos \varphi=0,8$ dari sumber listrik PLN untuk sistem 1 fasa 2 kawat tegangan 220 Volt dan frekuensi sistem $50 \mathrm{~Hz}$ maka besarnya arus pembeban adalah:

$\mathrm{I}=\frac{900}{220.0,8}=5,114$ Amper

Untuk arus nominal ( $\left.\mathrm{I}_{\mathrm{n}}\right)$ RCBO dipilih besarnya yang sama dengan arus pembebanan atau kalau tidak ada maka dipilih nilai yang lebih besar. Karena arus nominal $\left(\mathrm{I}_{\mathrm{n}}\right)$ RCBO tidak ada yang 5 Amper maka dipilih nilai arus nominal sebesar 6 Amper (sesuai yang ada di pasaran), dengan sensitifitas arus $((\mathrm{I} \Delta \mathrm{n}=30 \mathrm{~mA})$.

\section{KESIMPULAN}

Residual current circuit breaker with integral overload protection (RCBO) dapat digunakan untuk mengamankan instalasi rumah tinggal baik dari beban lebih (overload protection), hubung singkat (short circuit protection), dan juga terutama pengaman terhadap kejut listrik atau electric shock.

\section{DAFTAR PUSTAKA}

Quazani Abdallah dan Idir Habi, 2015. Protection of The people and Equipments in The Electric Installations. International Journal of Computer Science and Electronics Engineering (IJCSEE) Volume 3, Issue 1.

Hossein Mafi, Rami Yared, dan Layachi Bentabet, 2019. Smart Residual Current Circuit Breaker with Overload Protection. IEEE $2^{\text {nd }}$ 
International Conference on Renewable Sunarno. 2006. Mekanikal Elektrikal Lanjutan. Energy and Power Engineering. Penerbit Andi. Yogyakarta.

Jacques Schonek. 2006. Residual Current Devices in LV. Cahier Technique Schneider Electric no. 114.

Power Guide. 2009. Electrical Hazards and Protecting Persons. Legrand.

Schneider Electric. People Protection Against Electrocution.

Badan Standardisasi Nasional, 2011. Persyaratan Umum Instalasi Listrik (PUIL 2011): 6-7.

Buku 2. 11 Agustus 2010. Standar Konstruksi Sambungan Tenaga Listrik. PT. PLN (Persero).

Schneider Electric. 2007. Electrical Installation Guide.

Ashutosh Saxena, Supratim Ray, dan Rajiv K. Varma. 2002. A Novel Electric Shock Protection System Based On Contact Current on Skin Surface. National Power systems Conference (NPSC). Indian Institute of Technology Kanpur, India.

Syukriyadin. 2016. Sistem Proteksi Arus Bocor Menggunakan Earth Leakage Circuit Breaker Berbasis Arduino. Jurnal Rekayasa Elektrika. Volume 12, No.3.

Shashikumar K, Venkataseshaiah C, dan Sim Kok Swee. 2019. Smart Home Meter Profiler with Load Authentication, Shock Protection, Fault Proof and Restricted Demand Management. International Journal of Technology.

Dahari M. Siran. 2011. Residual Current Devices $(R C D)$ in Electrical Installations. National Conference on Electrical Safety, Malaysia.

Ing. Frantisek Stepan. 2017. Residual Current Diveces. Application Guide, Austria.

Schneider Electric Indonesia. 2019. Domae RCBO DOMD 016.

Diakses dari http:// www.plcdroid.com /2020 / 10 /pengertian-rcbo.html, tanggal 19 Maret 2021 jam 14.25 WITA. 